\title{
The Core/Shell Structure of CdSe/ZnS Quantum Dots Characterized by X-Ray Absorption Fine Spectroscopy
}

\author{
Huijing Wei, ${ }^{1,2}$ Jing Zhou, ${ }^{2}$ Linjuan Zhang, ${ }^{2}$ Fang Wang, ${ }^{1}$ Jianqiang Wang, ${ }^{2}$ and Chan Jin ${ }^{2}$ \\ ${ }^{1}$ College of Physics and Electronic Engineering, Henan Normal University, Henan 453007, China \\ ${ }^{2}$ Key Laboratory of Interfacial Physics and Technology, Shanghai Institute of Applied Physics, Chinese Academy of Sciences, \\ Shanghai 201800, China \\ Correspondence should be addressed to Chan Jin; jinchan@sinap.ac.cn
}

Received 15 December 2014; Revised 9 February 2015; Accepted 17 February 2015

Academic Editor: Hsueh-Shih Chen

Copyright (C) 2015 Huijing Wei et al. This is an open access article distributed under the Creative Commons Attribution License, which permits unrestricted use, distribution, and reproduction in any medium, provided the original work is properly cited.

\begin{abstract}
Understanding the chemical and physical properties of core/shell nanocrystal quantum dots (QDs) is key for their use in lightemission applications. In this paper, a single-step injection-free scalable synthetic method is applied to prepare high-quality core/shell QDs with emission wavelengths of $544 \mathrm{~nm}, 601 \mathrm{~nm}$, and $634 \mathrm{~nm}$. X-ray absorption fine structure spectra are used to determine the core/shell structure of CdSe/ZnS quantum dots. Moreover, theoretical XANES spectra calculated by FEFF.8.20 are used to determine the structure of Se and S compounds. The QD samples displayed nearly spherical shapes with diameters of approximately $3.4 \pm 0.5 \mathrm{~nm}(634 \mathrm{~nm}), 4.5 \pm 0.4 \mathrm{~nm}(601 \mathrm{~nm})$, and $5.5 \pm 0.5 \mathrm{~nm}(544 \mathrm{~nm})$. With XANES results and MS calculations, it is indicated that sphalerite $\mathrm{ZnS}$ capped with organic sulfur ligands should be the shell structure. Wurtzite CdSe is the main core structure with a Cd-Se bond length of $2.3 \AA$ without phase shift. This means that different emission wavelengths are only due to the crystal size with single-step injection-free synthesis. Therefore, single-step injection-free synthesis could generate a nearly ideal core/shell structure of CdSe/ZnS QDs capped with an organic sulfur ligand.
\end{abstract}

\section{Introduction}

Over the last 30 years, a significant amount of research has been reported regarding quantum dot (QD) synthesis. The fundamental physical properties and potential applications of quantum dots include multiplexed labeling and tracking of cells or molecules in a biological environment, downshifting light for color engineering in solid-state lighting, illumination and displays, and single-photon sources. Among various semiconductor materials, CdSe has been most extensively studied because its size-dependent photoluminescence is tunable across the visible spectrum [1-5], but it is insufficiently stable and is sensitive to the processing conditions and the environment $[6,7]$. To address these disadvantages, scientists have focused on the development of core/shell QDs, which incorporate a shell of wider band gap semiconductor materials around the QD cores [8-13]. These core/shell QDs have been shown to be generally more robust against chemical degradation and photooxidation [14-17].
Knowledge of the chemical and physical properties of semiconductor nanocrystals is a key issue in understanding the mechanisms of the dots formation and their position correlations. Many techniques have been used to determine information on their structural properties and ordering phenomena [18-21]. Element sensitive transmission electron microscopy (TEM) studies have provided information about the CdSe core structure and the surrounding $\mathrm{ZnSe}$ shells [22]. The CdSe/ZnS core/shell structure was elucidated using high-resolution TEM/STEM $[20,23]$. The structure of core/shell/shell CdSe/ZnSe/ZnS QDs was also studied using photoluminescence spectroscopy [24]. Recently, the structural evolution of the interfaces in $\mathrm{CdSe} / \mathrm{CdS}$ and $\mathrm{CdSe} / \mathrm{Cd}_{0.5} \mathrm{Zn}_{0.5} \mathrm{~S}$ colloidal QDs was investigated using surface-enhanced Raman spectroscopy [25]. However, not all of these techniques can reveal structural properties. Because of the small scattering volume of CdSe/ZnS QDs, it is not possible to obtain any information using high-resolution Xray diffraction (HRXRD). Therefore, the understanding of 
the local structure of these QDs and their environments is still rudimentary.

X-ray absorption near edge structure (XANES) [2628] and extended X-ray absorption fine structure (EXAFS) $[29,30]$ are sensitive to the oxidation state/site symmetry of elements and to the local structure around a selected atom. Recently, the core/shell structure of $\mathrm{CdSe}_{x} \mathrm{~S}_{1-x}$ QDs was explored using XANES and EXAFS [31]. The local structure of CdSe/ZnSe QDs was analyzed using EXAFS and diffraction anomalous fine structure (DAFS). XANES is largely a fingerprint for the oxidation state and site symmetry of an element. Meanwhile, theoretical XANES spectra were calculated using the ab initio multiple-scattering code FEFF8.20 [32,33]. Comparing the theoretical spectra with the experimental spectra can reveal detailed structural information about QDs. Therefore, we use both XAFS experimental data and XANES theoretical calculations to probe the fine structure of QDs obtained from a single-step injection-free synthesis.

In the previous work [12], we developed a single-step injection-free synthesis of high-quality core/shell QDs. We considered the QDs structure to be CdSe $/ \mathrm{Zn}_{x} \mathrm{Cd}_{1-x} \mathrm{~S}$. However, it is difficult to collect detailed structural information using conventional test methods. In this paper, the structural information of QDs is confirmed using EXAFS and XANES with MS calculations.

\section{Experiment Section}

2.1. Chemicals. Cadmium oxide (CdO, 99.99\%), selenium powder (Se, 100 mesh, 99.5\%), zinc nitrate hexahydrate $\left(\mathrm{Zn}\left(\mathrm{NO}_{3}\right)_{2} \cdot 6 \mathrm{H}_{2} \mathrm{O}, 98 \%\right)$, zinc acetate $\left(\mathrm{Zn}(\mathrm{OAc})_{2}, 99.99 \%\right)$, sulfur powder (S, 99.98\%), stearic acid (SA, 95\%), and 1octadecene (ODE, 90\%) were purchased from Aldrich.

2.2. QD Synthesis. The QDs were synthesized using a modification of Zhang's method [12]. First, $\mathrm{CdO}(0.205 \mathrm{~g}, 1.6 \mathrm{mmol})$, $\mathrm{Zn}\left(\mathrm{NO}_{3}\right)_{2} \cdot 6 \mathrm{H}_{2} \mathrm{O}(0.238 \mathrm{~g}, 0.8 \mathrm{mmol})$, Se (0.032 g, $\left.0.4 \mathrm{mmol}\right)$, and $S(0.026 \mathrm{~g}, 0.8 \mathrm{mmol})$ were added to a solution of TOP and SA in $20 \mathrm{~mL}$ of 1-octadecene (ODE) in a $100-\mathrm{mL}$ threenecked flask, which was fitted with a heating mantle, a condenser, and a temperature probe. Then, the mixture was heated to $250^{\circ} \mathrm{C}$ at a heating rate of $20-40^{\circ} \mathrm{C} / \mathrm{min}$ under a nitrogen atmosphere.

QDs with an emission wavelength of $544 \mathrm{~nm}$ were obtained by adding $0.3 \mathrm{~mL}$ TOP and $1.14 \mathrm{~g}$ ( $4 \mathrm{mmol}) \mathrm{SA}$. QDs with an emission wavelength of $601 \mathrm{~nm}$ were obtained by adding $0.4 \mathrm{~mL}$ TOP and $1.71 \mathrm{~g}(6 \mathrm{mmol}) \mathrm{SA}$. QDs with an emission wavelength of $534 \mathrm{~nm}$ were obtained by adding $3.0 \mathrm{~mL}$ TOP and $0.99 \mathrm{~g}(3.5 \mathrm{mmol}) \mathrm{SA}$ and substituting $\mathrm{Zn}\left(\mathrm{NO}_{3}\right)_{2}$ with $\mathrm{Zn}(\mathrm{OAc})_{2}$.

2.3. Characterization. Photoluminescence spectra (PL spectra) were obtained using an LS-45 (PerkinElmer) fluorescence spectrophotometer. Transmission electron microscopy (TEM) and high-resolution transmission electron microscopy (HRTEM) images were acquired using a field emission TEM (a FEI Tecnai G2 F20 S-Twin, 200 kV).
X-ray absorption fine spectroscopy (XAFS) data for the Se and Cd K-edge were collected on Beamline BL14W1 at the Shanghai Synchrotron Radiation Facility (SSRF). The incident radiation was filtered using a $\mathrm{Si}$ (311) doublecrystal monochromator with a suppression mirror system for focusing and harmonic rejection. All data were taken in transmission mode using an Oxford ion gas chamber. The Se K-edge spectra were calibrated by defining the zero crossing point of the second derivative of the XANES spectra for the Se reference foils as $12658 \mathrm{eV}$, and the Cd K-edge spectra were calibrated by defining the zero crossing point of the second derivative of the XANES spectra for the Cd reference foil as $26711 \mathrm{eV}$. The S K-edge X-ray absorption near edge structure (XANES) spectra were collected on Beamline 4B7A at the Beijing Synchronization Radiation Facility (BSRF). The sulfur K-edge spectrum of the QDs was obtained using a double-crystal monochromator (DCM) and recorded in Xray fluorescence yield (XFY) mode. The XAFS and XANES data were analyzed using the IFEFFIT software [34], and the cluster size dependence was determined using the ab initio multiple-scattering code FEFF8.20 [32,33].

\section{Results and Discussion}

3.1. Optical Properties. The nanocrystal quantum dots (QDs) were synthesized using the single-step injection-free approach, as shown in Figure 1(a), which produced highquality core/shell QDs [12]. The detailed procedures are described in the materials and methods. Briefly, $\mathrm{CdO}$, $\mathrm{Zn}\left(\mathrm{NO}_{3}\right)_{2}$, Se, and $\mathrm{S}$ were combined in an ODE solution con-taining TOP and SA at room temperature and then heated to $250^{\circ} \mathrm{C}$ under stirring. As shown in Figures 1(b)-1(c), the three samples have different colors under a UV lamp with emission wavelengths of $544 \mathrm{~nm}$ (green), $601 \mathrm{~nm}$ (yellow), and $634 \mathrm{~nm}$ (red). The symmetric and narrow band edge PL emission peak in the PL spectra indicates that the particle sizes and shapes are nearly uniform [12].

3.2. Morphology of Obtained QDs. The characterization of QD samples with three different emission wavelengths was performed using TEM and HRTEM, as shown in Figure 2. At different growth stages, the QD samples displayed nearly spherical shapes with diameters of approximately $3.4 \pm 0.5 \mathrm{~nm}$ $(634 \mathrm{~nm}), 4.5 \pm 0.4 \mathrm{~nm}(601 \mathrm{~nm})$, and $5.5 \pm 0.5 \mathrm{~nm}(544 \mathrm{~nm})$.

3.3. Structural Characterization of the QDs. To understand the relationship between the structure and the variation in the optical properties of the three QDs samples, X-ray absorption spectroscopy (XAS) was employed. X-ray absorption near edge structure (XANES) and extended X-ray absorption fine structure (EXAFS) data reduction was conducted using standard procedures [35]. XANES is largely a fingerprint for the oxidation state and site symmetry of the elements.

The S K-edge XANES spectra were collected to determine the $S$ compounds in the QD samples. Figure 3(a) shows the $S$ K-edge XANES spectra of the three QDs with emission wavelengths of $544 \mathrm{~nm}, 601 \mathrm{~nm}$, and $634 \mathrm{~nm}$. Two strong peaks are observed in the S K-edge spectra of the three samples. 


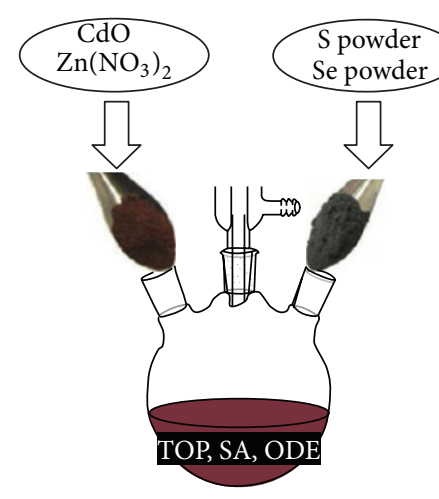

(a)

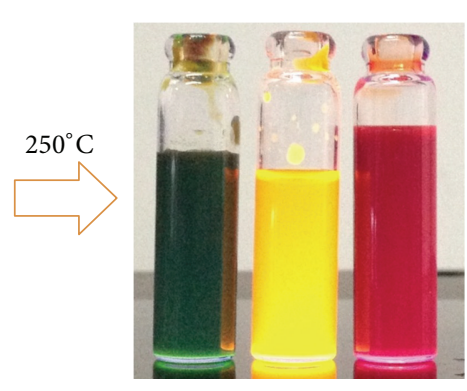

(b)

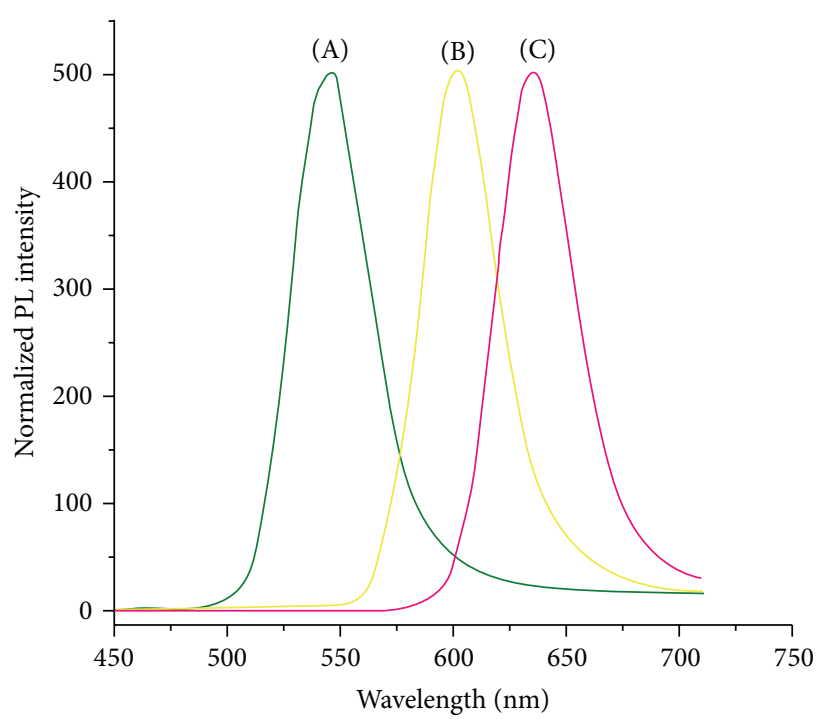

(c)

FIGURE 1: (a) Overall scheme for the single-step noninjection synthesis of QDs. (b) Photographs of typical emission color under the UV lamp. (c) PL emission spectra of obtained QDs with emission wavelengths of $544 \mathrm{~nm}$ (A), $601 \mathrm{~nm}$ (B), and 634 (C).

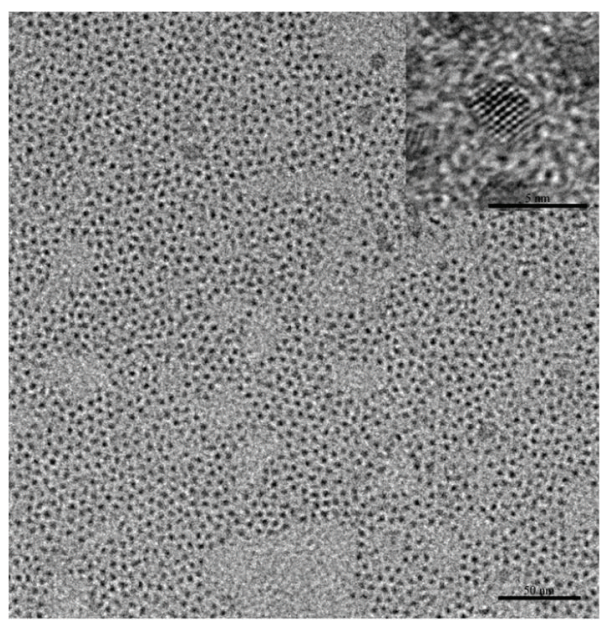

(a)

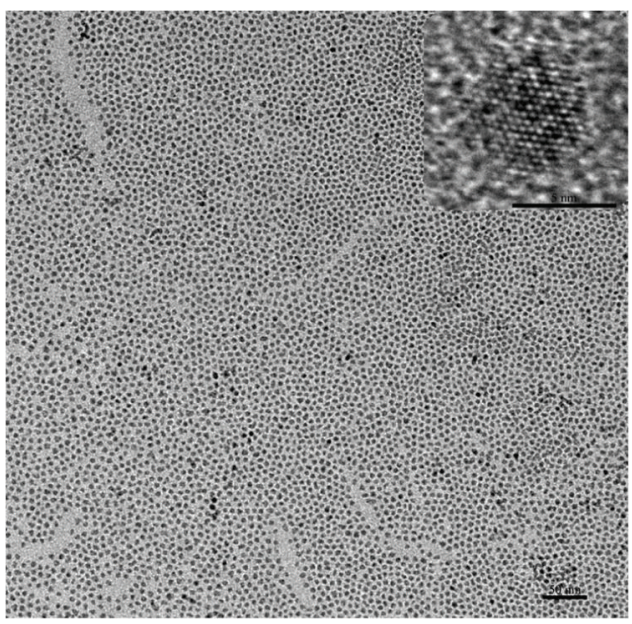

(b)

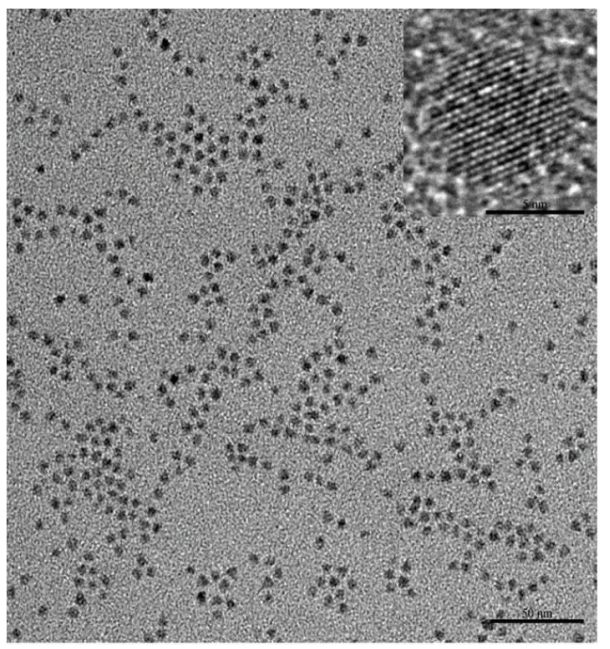

(c)

FIGURE 2: TEM and HRTEM images of obtained QDs with emission wavelengths of $634 \mathrm{~nm}(\mathrm{a}), 601 \mathrm{~nm}(\mathrm{~b})$, and $544 \mathrm{~nm}$ (c). 


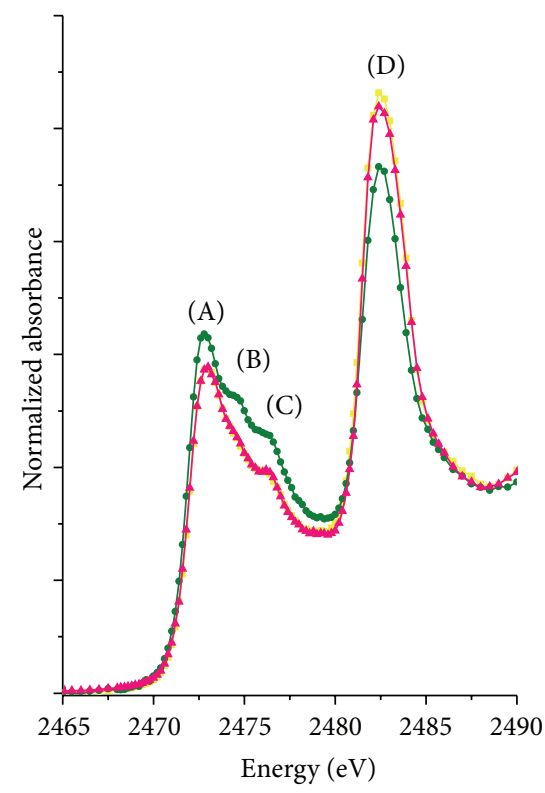

(a)

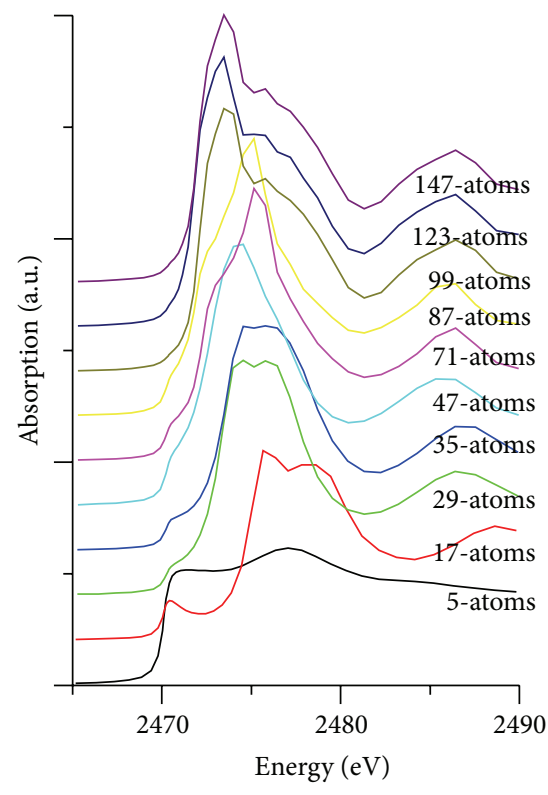

(b)

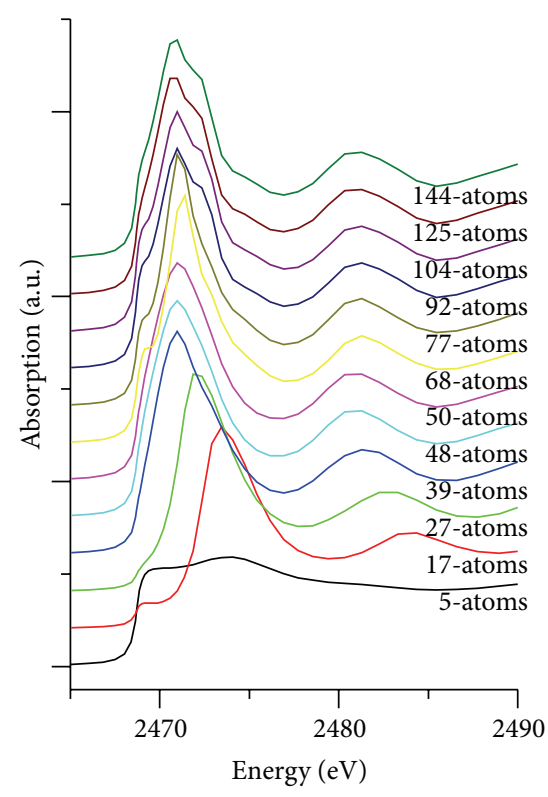

(c)

Figure 3: (a) The S K-edge XANES spectra of three obtained QDs with emission wavelengths of $544 \mathrm{~nm}$ (green), $601 \mathrm{~nm}$ (yellow), and $634 \mathrm{~nm}$ (red), and MS calculations of S K-edge XANES spectra in sphalerite ZnS (b) and wurtzite CdS (c) for different atomic clusters.

The first peak (A) is at approximately $2472 \mathrm{eV}$ with two small shoulder peaks (2474 eV and $2476 \mathrm{eV}$ ), and the second peak (D) is at approximately $2482 \mathrm{eV}$. This strong peak, indicated by the white line, arises from the 1 s to $3 p$ transition. The white-line energy shift is closely related to the oxidation state of sulfur. The energy shift of the white line in the S K-edge XANES spectra shows a nearly linear dependence on the oxidation state and varies by approximately $12.0 \mathrm{eV}$ from $\mathrm{S}^{-2}$ to $S^{+6}$ [36]. Thus, the first peak (A) in our samples might incorporate contributions from $\mathrm{S}^{-2}$, while the second peak (D) comes from $\mathrm{S}^{+4}$ or $\mathrm{S}^{+6}$. The possible sulfur compounds in $\mathrm{S}^{-2}$ are $\mathrm{ZnS}, \mathrm{CdS}$, and $\mathrm{Zn}_{x} \mathrm{Cd}_{1-x} \mathrm{~S}$, but it is difficult to distinguish these three sulfur compounds in the S K-edge XANES spectra. Additionally, organic sulfur ligands with sulfur in the $\mathrm{S}^{+4}$ or $\mathrm{S}^{+6}$ state cap the QDs.

To distinguish the structure of $S$ in the obtained QD samples, we performed MS calculations of the S K-edge XANES in sphalerite ZnS (Figure 3(b)) and CdS (Figure 3(c)) using different clusters [37]. For ZnS, using a central sulfur atom, the first shell contains only four coordinated zinc atoms and makes only a small contribution to the features of the spectrum. The 17-atom cluster gives rise to the whiteline peak $\mathrm{A}$, demonstrating the influence of the relatively strong backscattering of the $\mathrm{S}^{-2}$ ions [38]. Features B and C were reproduced using clusters larger than 99 atoms, which include atoms up to $6 \AA$ from the central sulfur atom, indicating that these peaks arise from "medium-range" contributions. There is a white peak A and a shoulder peak $\mathrm{B} / \mathrm{C}$ in the $\mathrm{S} \mathrm{K}$-edge XANES spectra, which indicates that $\mathrm{ZnS}$ should be a major component of the samples. The zinc-blend structure of CdS is stable at room temperature but transforms to the wurtzite phase above $95 \pm 5^{\circ} \mathrm{C}$ [31]. Therefore, we performed MS calculations of the S K-edge XANES in the wurtzite phase of CdS. For CdS, with a central sulfur atom, the first shell contains only four coordinated cadmium atoms and only makes a small contribution to the features of the spectrum. Prepeak A, the white-line peak B, and shoulder peak $C$ were produced in clusters larger than 92 atoms. Therefore, no prepeak A or shoulder peak $\mathrm{C}$ was observed in the S K-edge XANES spectra of the QD samples. Additionally, the white-line peak in CdS is in almost the same position as ZnS. Thus, we suggest that no CdS compounds exist in the obtained samples.

The Cd K-edge XANES spectra were also collected to determine the Cd compounds in the QD samples. Figure 4 shows the Fourier transform (FT) magnitudes of the $k^{2}$ weighted $\chi(k)$ function using a Kaiser-Bessel window and the $k$-range of 2.8-10.5 for all samples. There are two peaks at approximately $1.7 \AA$ and $2.3 \AA$ without a phase shift. Based on previous results [21, 31, 39-41], the Cd-Se bond has a peak between 2.0 and $3.2 \AA$ in the Cd K-edge RSF function. In our results, there is a peak at approximately $2.3 \AA$ without a phase shift, which was confirmed to be from the Cd-Se bond. Furthermore, there is a strong peak at approximately $1.7 \AA$ without a phase shift, which can be ascribed to the $\mathrm{Cd}-\mathrm{O}$ bond of TOPO-Cd [42]. In the case of the $\mathrm{Cd}: \mathrm{Se}=4: 1$ system, the extra Cd atoms cap the CdSe with TOPO attached to both free Cd and CdSe. Meanwhile, as the concentrations of TOP and SA increase, the Cd-O peak intensity decreases gradually, and the Cd-Se peak intensity simultaneously increases, which implies that higher TOP and SA concentrations facilitate the conversion of TOPO-Cd into CdSe. Based on the above results, the CdSe is considered the core of the obtained QDs and has a wurtzite structure. The $\mathrm{Cd}$ atoms are located at 


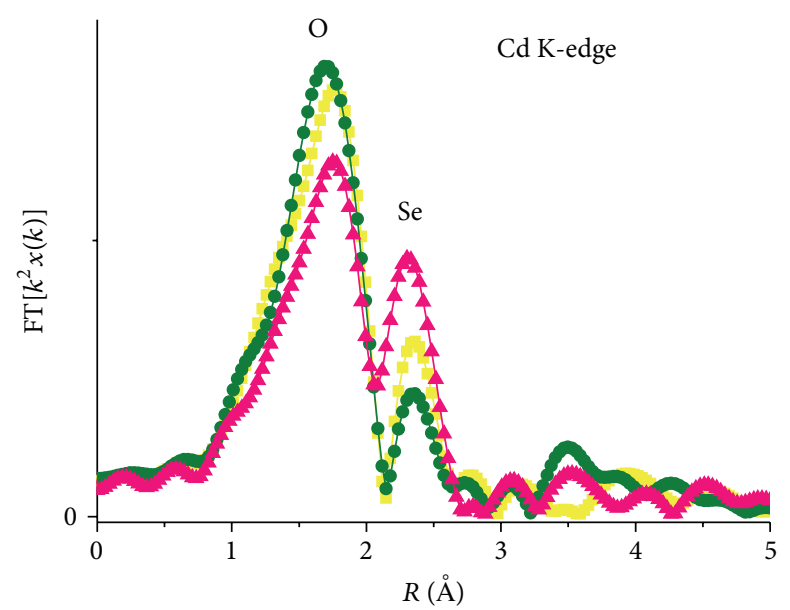

FIGURE 4: The magnitude of the Fourier transform (FT) of the $k^{2}$-weighted experimental EXAFS data of three obtained QDs with emission wavelengths of $544 \mathrm{~nm}$ (green), $601 \mathrm{~nm}$ (yellow), and $634 \mathrm{~nm}$ (red).

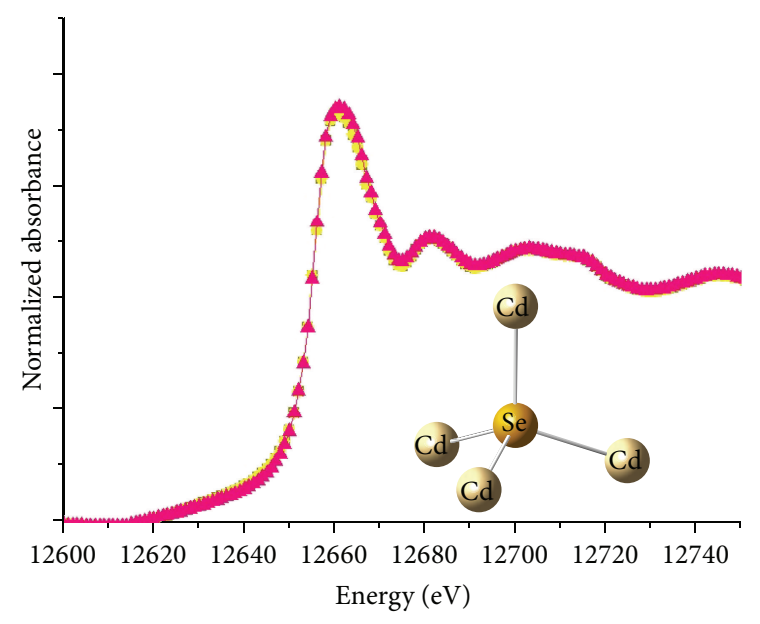

(a)

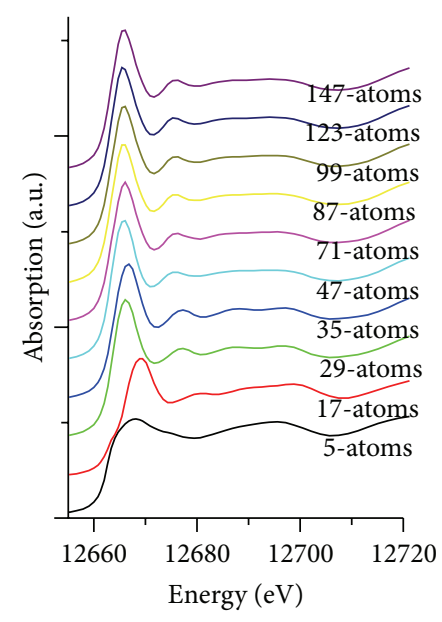

(b)

Figure 5: (a) The Se K-edge XANES spectra of three obtained QDs with emission wavelengths of $544 \mathrm{~nm}$ (green), $601 \mathrm{~nm}$ (yellow), and $634 \mathrm{~nm}$ (red), and (b) MS calculations of Se K-edge XANES spectra in wurtzite CdSe for different atomic clusters.

the tetrahedral sites of a face-centered cubic structure that consists of Se atoms.

The white lines and intensities in the Se K-edge XANES spectra of the QD samples (Figure 5(a)) are similar, indicating that the Se compounds in the three samples are nearly identical. With previous work [8,43-45], we considered that CdSe was the only compound for element Se in the QD samples. To distinguish the scattering contributions from the different coordination shells of CdSe, which has a wurtzite structure above $95 \pm 5^{\circ} \mathrm{C}$ [46], MS calculations of the Se Kedge XANES spectra were performed using different clusters, as shown in Figure 5(b). The results indicate that the XANES spectra for the 5-atom and 17-atom clusters with one and two shells are significantly different from the 29 -atom cluster and larger clusters with more than three shells. Compared with the XANES spectra of three samples, the results indicate that the QDs samples have more than 47 atoms, and the small clusters are in wurtzite structures.
Three QD samples with different emission wavelengths were obtained using the single-step injection-free synthesis. CdSe compounds with the narrowest band gap of $2.25 \mathrm{eV}$ $[47,48]$ exist in the center of the QD samples as the core structures. Meanwhile, $\mathrm{ZnS}$ compounds comprised the shell structures. Furthermore, the CdSe core structure has a wurtzite structure with a Cd-Se bond length of $2.3 \AA$ without phase shift, and the $\mathrm{ZnS}$ has a sphalerite structure. The core structure and shell structure are almost identical for the three different QD samples, which might be caused by the reaction stages. The single-step injection-free synthesis method combines all of the reactants in an ODE solution, which is then heated to $250^{\circ} \mathrm{C}$ with stirring. When the temperature is greater than $95 \pm 5^{\circ} \mathrm{C}$, CdSe exists only in the wurtzite phase. Based on this synthetic method, it can be concluded that the change in the QD emission wavelength is only caused by the size change due to the TOP and SA concentrations. Therefore, the single-step injection-free 
synthesis can generate a nearly ideal core/shell structure of $\mathrm{CdSe} / \mathrm{ZnS}$ QDs capped with sulfur organic ligands, and it can tune the emission wavelength from violet to near infrared.

\section{Conclusions}

A single-step injection-free scalable synthetic method was used to prepare core/shell QDs with different emission wavelengths. The core/shell structure of the QDs with three different emission wavelengths $(544 \mathrm{~nm}, 601 \mathrm{~nm}$, and $644 \mathrm{~nm}$ ) was performed using EXAFS and XANES with MS calculations. The structure of the CdSe (core) and ZnS (shell) in the three QD samples is nearly identical. The $\mathrm{XAFS}$ results show that $\mathrm{CdSe}$ is the main core component with a wurtzite structure and a Cd-Se bond length of $2.3 \AA$ without phase shift. They also indicate that the $\mathrm{ZnS}$ has a sphalerite structure, and the shell structure is capped with organic sulfur ligands with sulfur in the $\mathrm{S}^{+4}$ or $\mathrm{S}^{+6}$ state. Based on this synthetic method, it could be concluded that the changes in the QD emission wavelengths are only caused by the size changes of the nanocrystal, due to the TOP and SA concentrations. Therefore, this single-step injection-free synthesis could generate nearly ideal core/shell CdSe/ZnS QDs capped with organic sulfur ligands.

\section{Conflict of Interests}

The authors declare that there is no conflict of interests regarding the publication of this paper.

\section{Acknowledgments}

This work was financially supported by the National Key Technology R\&D Program (31-1122ZCKF), the State Key Development Program for Basic Research of China (2011BAK15B04), Natural Science Foundation of China (11105221), and the State Key Development Program for Basic Research of China (Grant no. 2010CB934501).

\section{References}

[1] D. C. Hannah, N. J. Dunn, S. Ithurria et al., "Observation of sizedependent thermalization in CdSe nanocrystals using timeresolved photoluminescence spectroscopy," Physical Review Letters, vol. 107, no. 17, Article ID 177403, 2011.

[2] E. A. Weiss, R. C. Chiechi, S. M. Geyer et al., "Size-dependent charge collection in junctions containing single-size and multisize arrays of colloidal CdSe quantum dots," The Journal of the American Chemical Society, vol. 130, no. 1, pp. 74-82, 2008.

[3] D. Katz, T. Wizansky, O. Millo, E. Rothenberg, T. Mokari, and U. Banin, "Size-dependent tunneling and optical spectroscopy of CdSe quantum rods," Physical Review Letters, vol. 89, no. 8, Article ID 086801, 2002.

[4] M. E. Schmidt, S. A. Blanton, M. A. Hines, and P. GuyotSionnest, "Size-dependent two-photon excitation spectroscopy of CdSe nanocrystals," Physical Review B: Condensed Matter and Materials Physics, vol. 53, no. 19, pp. 12629-12632, 1996.

[5] A. L. Rogach, A. Kornowski, M. Gao, A. Eychmüller, and H. Weller, "Synthesis and characterization of a size series of extremely small thiol-stabilized CdSe nanocrystals," The Journal of Physical Chemistry B, vol. 103, no. 16, pp. 3065-3069, 1999.

[6] P. Reiss, M. Protiere, and L. Li, "Core/shell semiconductor nanocrystals," Small, vol. 5, no. 2, pp. 154-168, 2009.

[7] M. D. Regulacio and M.-Y. Han, "Composition-tunable alloyed semiconductor nanocrystals," Accounts of Chemical Research, vol. 43, no. 5, pp. 621-630, 2010.

[8] W. Zhang, G. Chen, J. Wang, B.-C. Ye, and X. Zhong, "Design and synthesis of highly luminescent near-infrared-emitting water-soluble CdTe/CdSe/ZnS Core/Shell/Shell quantum dots," Inorganic Chemistry, vol. 48, no. 20, pp. 9723-9731, 2009.

[9] J. van Embden, J. Jasieniak, and P. Mulvaney, "Mapping the optical properties of $\mathrm{CdSe} / \mathrm{CdS}$ heterostructure nanocrystals: the effects of core size and shell thickness," Journal of the American Chemical Society, vol. 131, no. 40, pp. 14299-14309, 2009.

[10] B. J. Walker, P. M. Allen, and M. G. Bawendi, Abstracts of Papers of the American Chemical Society, American Chemical Society, 2010.

[11] J. R. Dethlefsen and A. Dossing, "Preparation of a ZnS shell on CdSe quantum dots using a single-molecular ZnS precursor," Nano Letters, vol. 11, no. 5, pp. 1964-1969, 2011.

[12] W. Zhang, H. Zhang, Y. Feng, and X. Zhong, "Scalable singlestep noninjection synthesis of high-quality core/shell quantum dots with emission tunable from violet to near infrared," ACS Nano, vol. 6, no. 12, pp. 11066-11073, 2012.

[13] W. Zhang, C. Jin, Y. Yang, and X. Zhong, "Noninjection facile synthesis of gram-scale highly luminescent CdSe multipod nanocrystals," Inorganic Chemistry, vol. 51, no. 1, pp. 531-535, 2012.

[14] J. Hensel, G. Wang, Y. Li, and J. Z. Zhang, "Synergistic effect of CdSe quantum dot sensitization and nitrogen doping of $\mathrm{TiO}_{2}$ nanostructures for photoelectrochemical solar hydrogen generation," Nano Letters, vol. 10, no. 2, pp. 478-483, 2010.

[15] J. Wang, I. Mora-Seró, Z. Pan et al., "Core/shell colloidal quantum dot exciplex states for the development of highly efficient quantum-dot-sensitized solar cells," Journal of the American Chemical Society, vol. 135, no. 42, pp. 15913-15922, 2013.

[16] A. Salant, M. Shalom, I. Hod, A. Faust, A. Zaban, and U. Banin, "Quantum dot sensitized solar cells with improved efficiency prepared using electrophoretic deposition," ACS Nano, vol. 4, no. 10, pp. 5962-5968, 2010.

[17] L. Liu, J. Hensel, R. C. Fizmorris, Y. Li, and J. J. Zhang, "Preparation and photoelectrochemical properties of $\mathrm{CdSe} / \mathrm{TiO}_{2}$ hybrid mesoporous structures," The Journal of Physical Chemistry Letters, vol. 1, no. 1, pp. 155-160, 2010.

[18] T. Schmidt, T. Clausen, J. Falta et al., "Correlated stacks of CdSe/ZnSSe quantum dots," Applied Physics Letters, vol. 84, no. 22, pp. 4367-4369, 2004.

[19] T. Schmidt, E. Roventa, T. Clausen et al., "Ordering mechanism of stacked CdSe $\mathrm{Zn} / \mathrm{S}_{x} \mathrm{Se}_{1-x}$ quantum dots: a combined reciprocal-space and real-space approach," Physical Review BCondensed Matter and Materials Physics, vol. 72, no. 19, Article ID 195334, 2005.

[20] M. A. van Huis, A. van Veen, H. Schut, S. W. H. Eijt, B. J. Kooi, and J. T. M. de Hosson, "Electron microscopy and positron annihilation study of CdSe nanoclusters embedded in MgO," Nuclear Instruments and Methods in Physics Research Section B: Beam Interactions with Materials and Atoms, vol. 218, no. 1-4, pp. 410-415, 2004. 
[21] A. Demourgues, G. N. Greaves, R. Bilsborrow, G. Baker, A. Sery, and B. Speit, "XAFS study of CdSe quantum dots in a silicate glass," Nuclear Instruments and Methods in Physics Research B, vol. 97, no. 1-4, pp. 166-168, 1995.

[22] D. Litvinov, A. Rosenauer, D. Gerthsen, and N. N. Ledentsov, "Character of the Cd distribution in ultrathin CdSe layers in a ZnSe matrix," Physical Review B: Condensed Matter and Materials Physics, vol. 61, no. 24, pp. 16819-16826, 2000.

[23] H. Shin, D. Jang, Y. Jang, M. Cho, and K. Park, "High resolution imaging analysis of CdSe/ZnS core-shell quantum dots (QDs) using Cs-corrected HR-TEM/STEM," Journal of Materials Science: Materials in Electronics, vol. 24, no. 10, pp. 3744-3748, 2013.

[24] B. C. Fitzmorris, J. K. Cooper, J. Edberg, S. Gul, J. Guo, and J. Z. Zhang, "Synthesis and structural, optical, and dynamic properties of core/shell/shell CdSe/ZnSe/ZnS quantum dots," Journal of Physical Chemistry C, vol. 116, no. 47, pp. 2506525073, 2012.

[25] A. M. Kelley, Q. Q. Dai, Z.-J. Jiang, J. A. Baker, and D. F. Kelley, "Resonance Raman spectra of wurtzite and zincblende CdSe nanocrystals," Chemical Physics, vol. 422, pp. 272-276, 2013.

[26] S. Tanaka, M. Kitta, T. Tamura, T. Akita, Y. Maeda, and M. Kohyama, "First-principles calculations of O-K ELNES/XANES of lithium titanate," Journal of Physics D: Applied Physics, vol. 45, no. 49, Article ID 494004, 2012.

[27] H. Murata, K. Shitara, I. Tanaka, A. Nakahira, T. Mizoguchi, and K. Matsunaga, "First-principles calculations of Zn-K XANES in Ca-deficient hydroxyapatite," Journal of Physics: Condensed Matter, vol. 22, no. 38, Article ID 384213, 2010.

[28] D. Cabaret, F. Mauri, and G. S. Henderson, "Oxygen K-edge XANES of germanates investigated using first-principles calculations," Physical Review B: Condensed Matter and Materials Physics, vol. 75, no. 18, Article ID 184205, 2007.

[29] P. H. Citrin, "Basic principles of exafs applied to simple and complex systems," Bulletin of the American Physical Society, vol. 22, no. 3, p. 359, 1977.

[30] V. Krishnan, M. P. Feth, E. Wendel, Y. Chen, M. Hanack, and H. Bertagnolli, "EXAFS spectroscopy-fundamentals, measurement techniques, data evaluation and applications in the field of phthalocyanines," Zeitschrift für Physikalische Chemie, vol. 218, no. 1, pp. 1-15, 2004.

[31] L. Y. Chen, C. H. Chen, C. H. Tseng, F. L. Lai, and B. J. Hwang, "Synthesis $\mathrm{CdS} \mathrm{e}_{x} \mathrm{~S}_{1-x}$ core/shell type quantum dotsvia one injection method," Chemical Communications, vol. 47, no. 5, pp. 1592-1594, 2011.

[32] K. Nakanishi and T. Ohta, "Verification of the FEFF simulations to K-edge XANES spectra of the third row elements," Journal of Physics: Condensed Matter, vol. 21, no. 10, Article ID 104214, 2009.

[33] E. Bosman and J. Thieme, "Modeling of XANES-spectra with the FEFF-program," in Proceedings of the 9th International Conference on X-Ray Microscopy, vol. 186, Zurich, Switzerland, July 2009.

[34] M. Newville, "IFEFFIT: interactive XAFS analysis and FEFF fitting," Journal of Synchrotron Radiation, vol. 8, no. 2, pp. 322324, 2001

[35] H. L. Bao, J. Li, L. H. Jiang et al., "Structure of PtnNi nanoparticles electrocatalysts investigated by X-ray absorption spectroscopy," Journal of Physical Chemistry C, vol. 117, no. 40, pp. 20584-20591, 2013.

[36] G. P. Huffman, F. E. Huggins, N. Shah et al., "Characterization of fine particulate matter produced by combustion of residual fuel oil," Journal of the Air and Waste Management Association, vol. 50, no. 7, pp. 1106-1114, 2000.

[37] Z. Y. Wu, G. Ouvrard, S. Lemaux et al., "Sulfur K-edge $\mathrm{X}$-ray-absorption study of the charge transfer upon lithium intercalation into titanium disulfide," Physical Review Letters, vol. 77, no. 10, pp. 2101-2104, 1996.

[38] F. E. Huggins, N. Shah, G. P. Huffman, and J. D. Robertson, "XAFS spectroscopic characterization of elements in combustion ash and fine particulate matter," Fuel Processing Technology, vol. 65 , pp. 203-218, 2000.

[39] M. Uehara, Z. H. Sun, H. Oyanagi et al., "In situ extended Xray absorption fine structure study of initial processes in CdSe nanocrystals formation using a microreactor," Applied Physics Letters, vol. 94, no. 6, Article ID 063104, 2009.

[40] Z. H. Sun, H. Oyanagi, M. Uehara et al., "Study on initial kinetics of CdSe nanocrystals by a combination of in situ X-ray absorption fine structure and microfluidic reactor," The Journal of Physical Chemistry C, vol. 113, no. 43, pp. 18608-18613, 2009.

[41] E. Piskorska-Hommel, V. Holý, O. Caha et al., "Complementary information on CdSe/ZnSe quantum dot local structure from extended X-ray absorption fine structure and diffraction anomalous fine structure measurements," Journal of Alloys and Compounds, vol. 523, pp. 155-160, 2012.

[42] S. N. Sharma, H. Sharma, G. Singh, and S. M. Shivaprasad, "Low energy ion induced effects on TOPO capped CdSe nanocrystals probed by XPS depth profiling and optical measurements," Nuclear Instruments and Methods in Physics Research, Section B: Beam Interactions with Materials and Atoms, vol. 244, no. 1, pp. 86-90, 2006.

[43] Z. Fang, L. Liu, J. Wang, and X. Zhong, "Depositing a ZnxCd1$\mathrm{xS}$ shell around cdse core nanocrystals via a noninjection approach in aqueous media," Journal of Physical Chemistry C, vol. 113, no. 11, pp. 4301-4306, 2009.

[44] X. H. Zhong, Y. Y. Feng, and Y. L. Zhang, "Facile and reproducible synthesis of red-emitting CdSe nanocrystals in amine with long-term fixation of particle size and size distribution," The Journal of Physical Chemistry C, vol. 111, no. 2, pp. 526-531, 2007.

[45] X. H. Zhong, R. G. Xie, Y. Zhang, T. Basché, and W. Knoll, "High-quality violet- to red-emitting $\mathrm{ZnSe} / \mathrm{CdSe}$ core/shell nanocrystals," Chemistry of Materials, vol. 17, no. 16, pp. 40384042, 2005.

[46] K. B. Subila, G. K. Kumar, S. M. Shivaprasad, and K. G. Thomas, "Luminescence properties of CdSe quantum dots: role of crystal structure and surface composition," Journal of Physical Chemistry Letters, vol. 4, no. 16, pp. 2774-2779, 2013.

[47] K. Tvrdy, P. A. Frantsuzov, and P. V. Kamat, "Photoinduced electron transfer from semiconductor quantum dots to metal oxide nanoparticles," Proceedings of the National Academy of Sciences of the United States of America, vol.108, no. 1, pp. 29-34, 2011.

[48] Z. Pan, K. Zhao, J. Wang, H. Zhang, Y. Feng, and X. Zhong, "Near infrared absorption of $\mathrm{CdS} e_{x} T e_{1-x}$ alloyed quantum dot sensitized solar cells with more than $6 \%$ efficiency and high stability," ACS Nano, vol. 7, no. 6, pp. 5215-5222, 2013. 

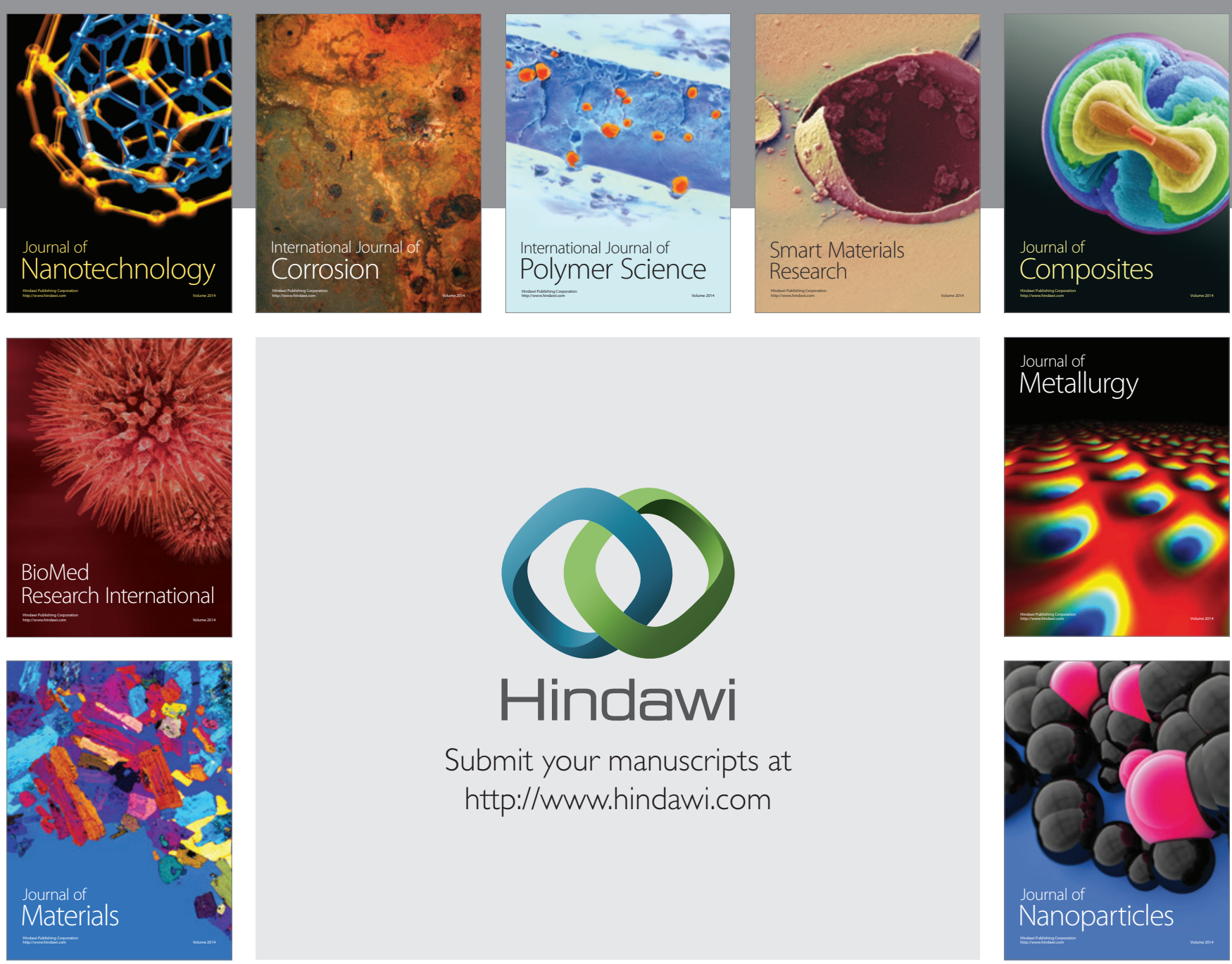

Submit your manuscripts at http://www.hindawi.com
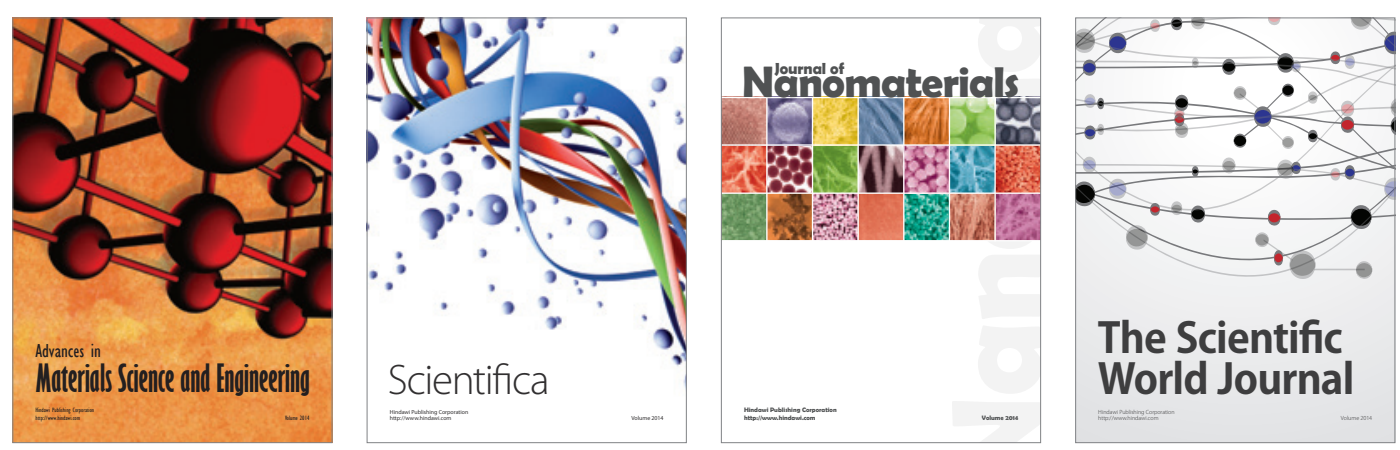

\section{The Scientific World Journal}
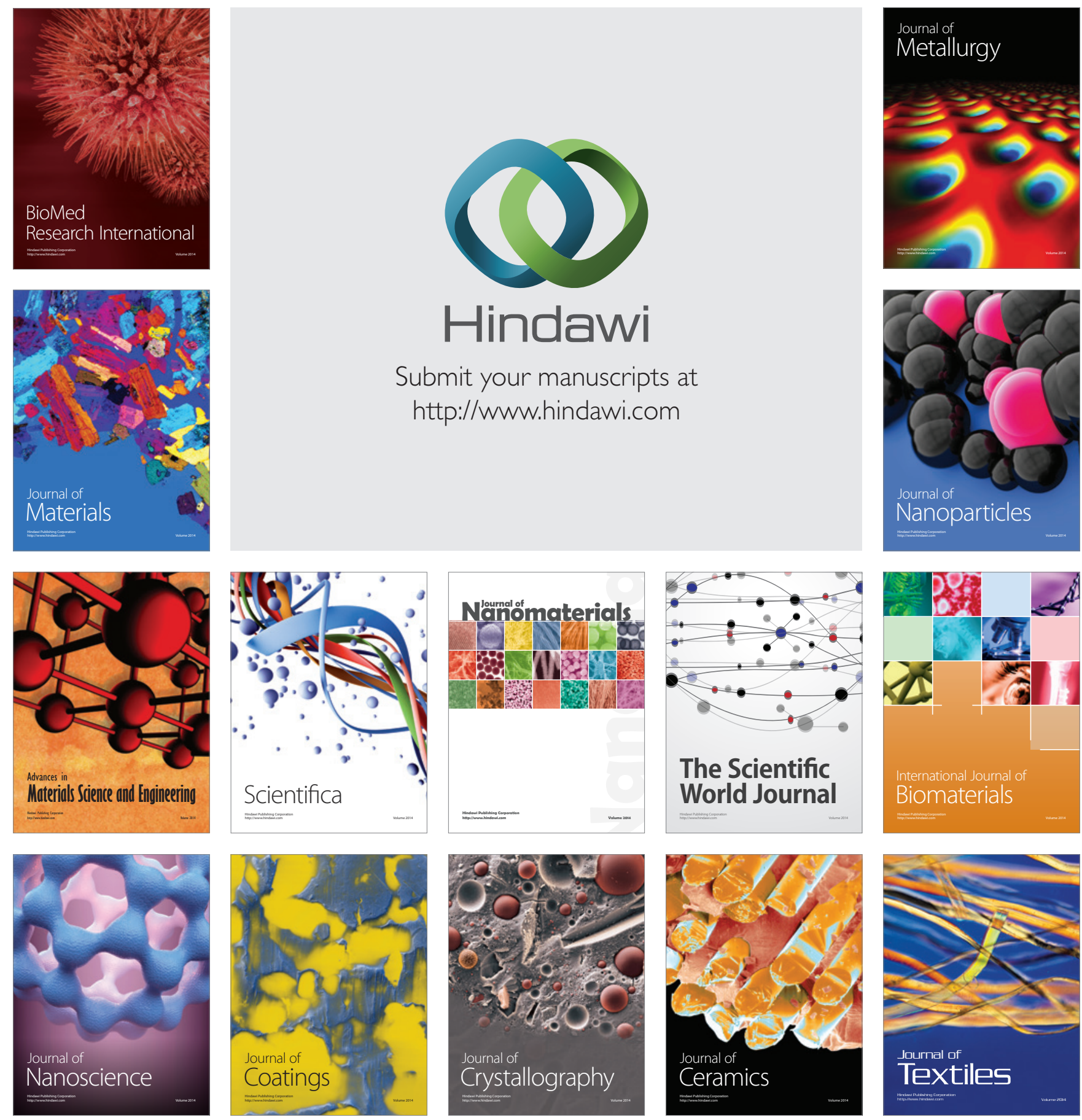